\title{
THE APPLICATION OF COMPOSITE MATERIALS IN THE AEROSPACE INDUSTRY
}

\author{
Jakub Skoczylas ${ }^{1 \Xi}$, Sylwester Samborski², Mariusz Kłonica ${ }^{3}$ \\ $1 \square$ Lublin University of Technology, Department of Applied Mechanics, 36 Nadbystrzycka Street, 20-618 Lublin, \\ Poland; orcid.org/0000-0002-7112-1323; email: j.skoczylas@pollub.pl \\ 2 Lublin University of Technology, Department of Applied Mechanics, 36 Nadbystrzycka Street, 20-618 Lublin, \\ Poland; email: s.samborski@pollub.pl \\ ${ }^{3}$ Lublin University of Technology, Department of Production Engineering, 36 Nadbystrzycka Street, 20-618 Lublin, \\ Poland; +48815384231, orcid.org/0000-0001-6149-1710, email: m.klonica@pollub.pl
}

Submitted: 2019-01-19 / Accepted: 2019-02-27 / Published: 2019-03-01

\section{ABSTRACT}

The paper investigates the growing popularity of composite materials concentrating on explanation of their advantages, especially taking into consideration composite materials used in the aerospace industry such as polymer matrix composites, metal matrix composites, ceramic matrix composites and smart composite materials. Various types of matrices and fibers are described with special emphasis on nanotechnology and opportunities to improve the properties of composites. The paper also presents selected examples of applications in the aerospace industry.

KEYWORDS: composite materials, aerospace industry, fiber, matrix

\section{Introduction}

In the aerospace industry it is essential to constantly look for modern materials which possess a better durability and give the opportunity to get the structure of a lighter weight ensuring safety of the highest level as well. Materials with enhanced characteristics are needed for aerospace systems with improved performance. Properties such as a high strength, high temperature resistance, fatigue resistance, fracture toughness, etc. should be as high as possible while density and cost are supposed to be minimized.

Composite materials are built from one or a greater number of components which possess different properties. Each composite material consists of a matrix and a reinforcement. Matrix takes up to $10-80 \%$ of an entire composite content and it is a uniform material filling the space between reinforcement parts. The role of a matrix is to make a joint for the reinforcement, to protect it and to transfer external stresses into it. Moreover, the matrix molds the desired shape of the part produced, while the reinforcement is responsible for all other properties of a composite material [1].

Nowadays, composite materials are in common use. In comparison to metals they possess a higher stiffness, mechanical strength [1], a better corrosion, higher fatigue resistance and a higher specific strength [2]. Mechanical, physical and chemical properties are constantly improved thanks to the development of nanotechnology which gives the chance to obtain nanocomposites that possess better properties than conventional composites, by only adding a small amount of nanoparticles such as carbon nanotubes, graphite flakes, etc. [3]. Therefore the use of composite materials in the aerospace industry has been rising in recent years. Materials of that kind show a big potential in both 
structural applications and some engine parts. Composites now constitute about $25 \%$ of the Airbus A380 aircraft, as shown in Fig. 1 [2]. The structure of the Boeing 787 Dreamliner including the fuselage, wings, doors, tails and interior is made of over $50 \%$ by weight composites ( $80 \%$ by volume) which makes it the first composite aircraft in production [4]. The percentage of total structural weight attributed to composites for selected aircrafts is illustrated in Fig. 2 [2].

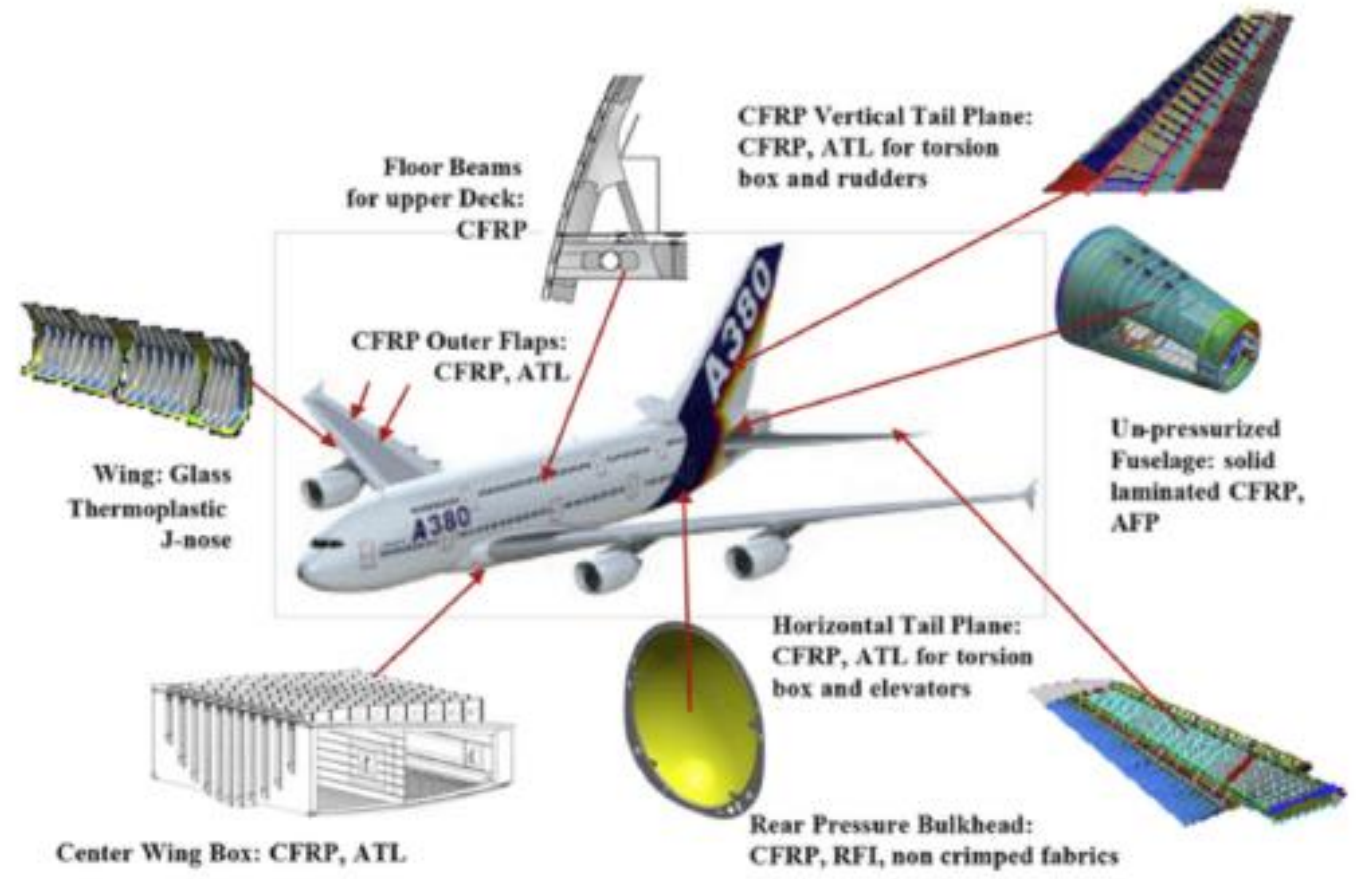

Fig. 1 The use of composites in Airbus A380 aircraft [2]

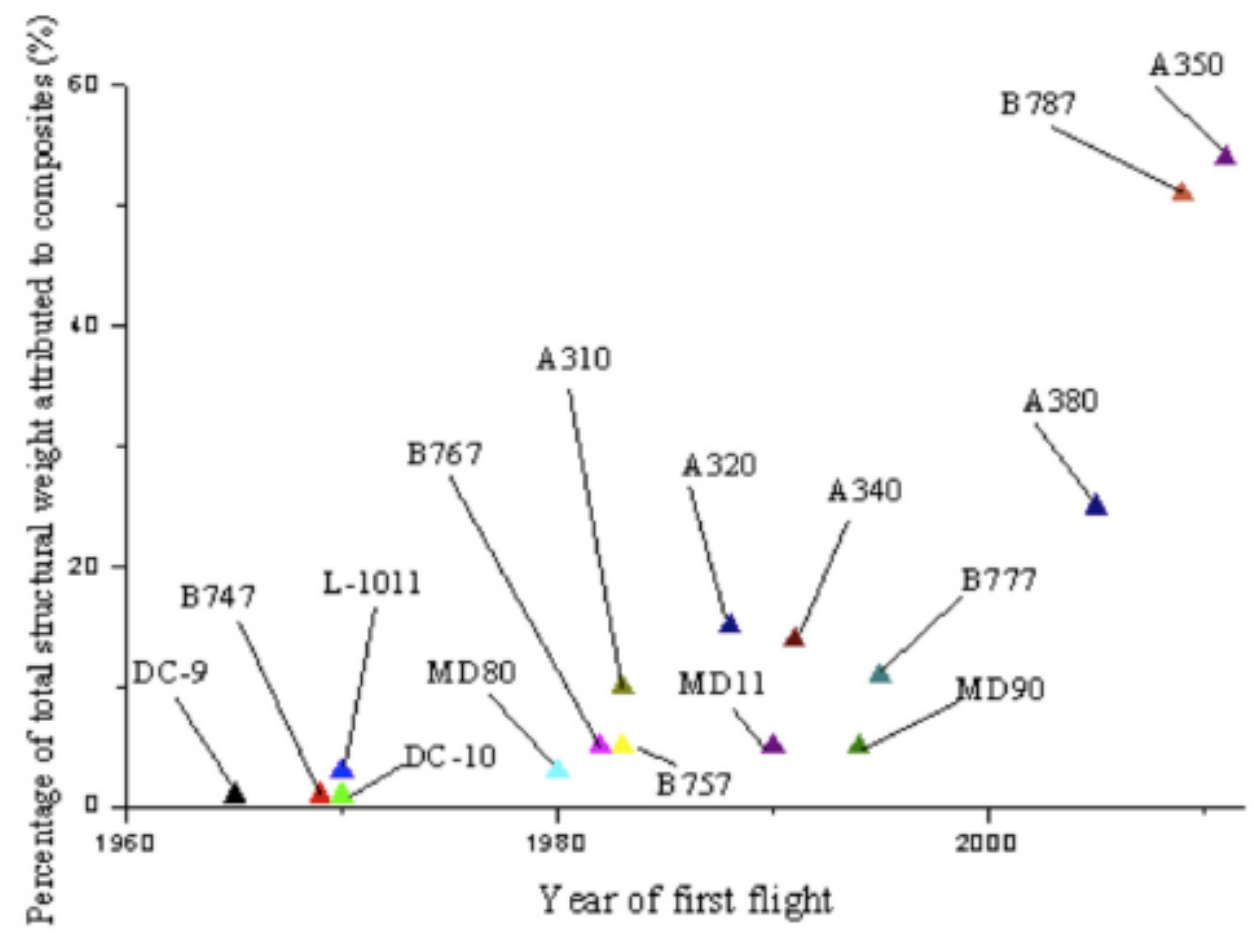

Fig. 2 The percentage of total structural weight attributed to composites [2]

Composite materials could be properly designed to guarantee services they are made for [5]. Industrial materials companies now develop new solutions based on composites to be applied in aircraft. For example, Hexcel has introduced HexWeb ${ }^{\circledR}$ Acousti-Cap consisting of permeable cap 
material embedded into honeycomb core which helps the Boeing $737 \mathrm{MAX}$ engine to reduce noise during take-off and landing. Moreover, Diabgroup supplies Divinycell $\mathrm{F}-\mathrm{a}$ thermoplastic foam used for seats and interior of e.g. Airbus A350 XWB [6].

In the aerospace industry the most commonly used group of composite materials are fibrous composites in which reinforcements are made mostly of the following fibers: glass, carbon or aramid [1]. Differences in structures of the fibers result in important differences in the properties of the fibers and in the properties of entire composites [4]. Matrices can be made of polymer (polymer matrix composite $\mathrm{PMC}$ ), ceramic (ceramic matrix composite $\mathrm{CMC}$ ) and metal (metal matrix composite $\mathrm{MMC}$ ).

\section{Polymer matrix composites}

There are two categories of polymer matrix composites (PMC) based on the different matrix characteristics: thermoplastics (polypropylene, Nylon 6.6, PMMA, PEEK) and thermosets (epoxy, polyester, phenolic and polyimide resins). Both of them have been used for aerospace structure applications. The main advantages of PMCs are their high specific strength and specific modulus. For example, the density of the carbon fiber reinforced epoxy composite is just half that of Al-based alloys, whereas the elastic modulus and tensile strength are two times and three times higher, respectively, than those of the Al-based alloy [7].

PMCs include e.g. a carbon fiber reinforced polymer (CFRP), a glass fiber reinforced polymer (GFRP), an aramid fiber reinforced polymer. A glass fiber reinforced polymer (GFRP) has been applied in semi-structural components (e.g. fairings). Where a high impact resistance is required aramid fiber polymers are used [8].

However, the most widely used aerospace structural material apart from aluminum alloys is a carbon fiber reinforced polymer (CFRP). It has been applied in production of structural components of the fuselage, empennage and wing box, as well as the control surfaces such as rudder, ailerons, elevator, flaps and landing-gear doors. Boeing 777 and 787 aircraft have up to half of their weight in CFRP [2], [8]. Although carbon fibers can improve the strength of PMCs they are supposed to cause stress concentration in CFRPs because of their brittleness. Therefore many researchers now focus on alternative fibers for PMCs such as carbon nanotubes (CNT), graphene, basalt and natural fibers [2]. However, the ablation-resistance performance of carbon fiber reinforced poly(silacetylene) composites has significantly increased by adding rigid phenyl groups into their matrices. It would make them good candidates for advanced thermal protection materials [9].

Moreover, it was reported that graphene based polymer composites possess much better mechanical properties than CNT reinforced PMCs. Adding only $0.1 \mathrm{wt} \%$ graphene oxide to an epoxy composite could cause an increase of the tensile strength from $53 \mathrm{MPa}$ to $72 \mathrm{MPa}$. Besides, another effective reinforcement in PMCs is basalt. Researches in their practical tests showed that the tensile strength, tensile modulus, flexural strength and flexural modulus of polybutylene succinate continuously increased when basalt fiber content was added [10], [11], [12].

Furthermore, natural fibers are being used to improve the mechanical properties of polymer matrix composites. Examples of natural fibers used in PMCs are flax, hemp, banana, bamboo and recycled cellulose fiber (RCF) [13]. Natural fiber reinforced PMCs and carbon nanotube reinforced PMCs have been extensively applied in military aircraft, in structure components and conductive coating for fighter jets [2].

One of the main disadvantages of PMCs is the low flame resistance of the matrix which could reduce their use in aircraft components in the areas where the high flame resistance is crucial. However, it was observed that adding a small amount (1-3 wt\%) of bentonites modified with quaternary ammonium or phosphonium salts could increase the mechanical properties and flame resistance of GFRPs [14]. 


\section{Metal matrix composites}

Another important group of composite materials that have applications in the aerospace industry are metal matrix composites ( $\mathrm{MMC}$ ) which possess a high yield strength, fracture toughness, low thermal expansion and proper wear resistance. Metals such as aluminum, magnesium, titanium, copper and nickel were studied as the matrices for MMCs [2]. Aluminum based composites have superior mechanical and physical properties (as compared to base alloy) appropriate for aerospace applications [15]. Aluminum based MMC reinforced by $30 \%$ SiC possesses a similar density as 2219 Al-based alloys but even a $70 \%$ higher specific modulus, $60 \%$ higher elastic modulus and $15 \%$ higher tensile strength [16].

Conventional carbon and ceramic fibers do not have a potential to improve the properties of MMCs. Because of the growing demand for fibers with a higher strength, a lower coefficient of thermal expansion, better self-lubricant ability and a higher damping capacity, the use of carbon nanotubes (CNT) and graphene has become more important [17].

One of the most frequently used fiber metal laminates (FML) is glass fiber reinforced aluminum (GLARE) which has been applied e.g. in the fuselage skin and empennage of Airbus A380. GLARE is a hybrid material that consists of 2-6 aluminum layers with thickness from 0.2 to $0.5 \mathrm{~mm}$. Fibers and metal are placed alternately between the layers and bonded with an epoxy resin matrix. GLARE possesses a low density, high strength, high stiffness, fatigue resistance and corrosion resistance compared to monolithic metals. GLARE is more expensive than aluminum and other composite materials [1], [8].

Furthermore, a separate group of MMCs are intermetallic matrix composites (IMC). The example of application IMCs using titanium aluminides is General Electric GE90 - a turbofan engine produced by GE Aviation for Boeing 777. Thanks to applying IMCs a total weight of the engine was reduced by $150 \mathrm{~kg}[18]$.

\section{Ceramic matrix composites}

Ceramic matrix composites (CMC) have been extensively investigated due to their good properties, such as high hardness (23 GPa for an alumina based composite), high-temperature stability, high corrosion resistance and satisfactory versatility. Apart from alumina, matrices for CMCs are mainly based on silicon carbide, silicon nitride, aluminum titanate, aluminum nitride and zirconia [2].

Since CMCs are able to withstand operating temperature at $1400^{\circ} \mathrm{C}$ they are applied in hightemperature sections in aircraft e.g. an exhaust nozzle. Moreover, the carbon fiber reinforced silicon carbide is a suitable material for aircraft brakes where the temperature could reach up to $1200^{\circ} \mathrm{C}$ [19].

To improve the fracture toughness of CMCs, nanomaterials such as the carbon nanotubes and graphene have been added. The increase of $235 \%$ in fracture toughness of a silicon nitride based ceramic composite was observed by adding 1.5 vol\% of graphene [20]. Another research proved that the fracture toughness of an alumina based ceramic composite increased when graphene content rose from 0 to 0.38 vol\% but then, the fracture toughness started to decrease while more graphene was added. Therefore the content of graphene should be limited at critical value [21].

\section{Smart composites}

There are some different kinds of smart composite materials that have a high potential for use in aircraft: shape memory polymer composites (SMPC) and self-healing composites [2], [8]. SMPCs are intelligent materials that are able to change their form (from their distorted form to original) in the effect of, e.g. changing temperature or an electric/magnetic field, by releasing the internal stress stored in the material. Although SMPCs are not the only one shape memory materials, they are probably the most widely used because they have many advantages over, e.g. shape memory alloys 
such as a higher shape deformability and recoverability, a lower density and a relatively lower cost. SMPCs have been applied in the skin of morphing-wing aircraft and the solar array and reflector antenna of satellites [22].

Self-healing composites include polymer, metal or ceramic matrix composites. The healing agents are mosaicked in the matrix. The use of self-healing mechanism could cause the increasing of the damage tolerance and life of composites [8]. The self-healing materials containing boron can be potentially applied in the aerospace industry for aircraft engine parts. Boron trioxide may seal matrix cracks at high temperatures to heal microcracks before crack growth to failure. Additionally, self-healing epoxy composite materials can recover their protect ability after damages so they can be used to protect aircraft structures from corrosion by coating [23].

\section{Conclusions}

For over 10 years the gaining popularity of composite materials in the aerospace industry has been observed. Many composite materials have been investigated as candidates to applications in aircraft. In light-weight considerations they are definitely a better choice than metals. The most widely applied composite materials in the aerospace industry are CFRPs. Nevertheless, it needs to be emphasised the aerospace industry is still developing and in the near future there still will be demand for newer materials that possess better and better properties and a higher endurance. There are certainly a lot of opportunities for researchers in this field of science.

Another interesting aspect related to using composite materials is the method of joining them. In the aerospace industry adhesive bonding appears to be the most suitable alternative for riveting and screwing because of a low weight growth of the aircraft - the weight of glue is relatively low. Hence, specific kinds of adhesives should be investigated for aerospace applications according to high requirements.

\section{References}

[1] R. Bielawski, W. Rządkowski, S. Augustyn, P. Pyrzanowski, "Nowoczesne materiały stosowane w konstrukcjach lotniczych - wybrane problemy oraz kierunki rozwoju", Zeszyty Naukowe Politechniki Rzeszowskiej. Mechanika., vol. 87, no. 3, pp. 203-216, 2015.

[2] Xuesong Zhang, Yongjun Chen, Junling Hu, "Recent advances in the development of aerospace materials", Progress in Aerospace Sciences, vol. 97, pp. 22-34, 2018.

[3] J. Baur, E. Silverman, "Challenges and opportunities in multifunctional nanocomposite structures for aerospace applications", MRS Bull, vol. 32, no. 4, pp. 328-334, 2011.

[4] C. Soutis, "Introduction: Engineering requirements for aerospace composite materials", Polymer Composites in the Aerospace Industry, pp. 1-18, 2015.

[5] C. Barile, C. Casavola, F. De Cillis, "Mechanical comparison of new composite materials for aerospace applications", Composites Part B: Engineering, vol. 162, pp. 122-128, 2019.

[6] M. Holmes, "Aerospace looks to composites for solutions", Reinforced Plastics, vol. 61, no. 4, pp. 237-241, 2017.

[7] R. M. Wang, S. R. Zheng, Y.G. Zheng, Polymer Matrix Composites and Technology, Elsevier, 2011.

[8] L. Zhu, N. Li, P. R. N. Childs, "Light-weighting in aerospace component and system design", Propulsion and Power Research, vol. 7, no. 2, pp. 103-119, 2018.

[9] Lei Kong, Xiaobiao Zuo, Shipeng Zhu, et al., "Novel carbon-poly(silacetylene) composites as advanced thermal protection material in aerospace applications", Composites Science and Technology, vol. 162, pp. 163-169, 2018.

[10] T. Kuilla, S. Bhadra, D. Yao, et al., "Recent advances in graphene based polymer composites", Progress in Polymer Science, vol. 35, no. 11, pp. 1350-1375, 2010. 
[11] Y. J. Wan, L. X. Gong, L. C. Tang, L. B. Wu, J. X. Jiang, "Mechanical properties of epoxy composites filled with silane-functionalized graphene oxide", Composites Part A: Applied Science and Manufacturing, vol. 64, pp. 79-89, 2014.

[12] Y. Zhang, C. Yu, P. K. Chu, et al., "Mechanical and thermal properties of basalt fiber reinforced poly (butylene succinate) composites", Materials Chemistry and Physics, vol. 133, no. 2-3, pp. 845-849, 2012.

[13] N. Saba, M. Jawaid, Othman Y. Alothman, M. T. Paridah, "A review on dynamic mechanical properties of natural fibre reinforced polymer composites", Construction and Building Materials, vol. 106, pp. 149-159, 2016.

[14] R. Oliwa, M. Heneczkowski, M. Oleksy, "Kompozyty epoksydowe do zastosowań w przemyśle lotniczym", Polimery, vol. 60, no. 3, pp. 167-178, 2015.

[15] D. K. Koli, G. Agnihotri, R. Purohit, "Advanced Aluminium Matrix Composites: The Critical Need of Automotive and Aerospace Engineering Fields", Materials Today: Proceedings, vol. 2, no. 4-5, pp. 3032-3041, 2015.

[16] T. Prater, "Friction stir welding of metal matrix composites for use in aerospace structures", Acta Astronautica, vol. 93, pp. 366-373, 2014.

[17] Sie Chin Tjong, "Recent progress in the development and properties of novel metal matrix nanocomposites reinforced with carbon nanotubes and graphene nanosheets", Materials Science and Enineering: R: Reports, vol. 74, no. 10, pp. 281-350, 2013.

[18] J. Konieczny, "Materiały stosowane w konstrukcjach lotnictwa wojskowego", Armia, vol. 56, no. 4, pp. 68-75, 2013.

[19] S. Fan, C. Yang, L. He, Y. Du, W. Krenkel, P. Greil and N. Travitzky, "Progress of ceramic matrix composites brake materials for aircraft application", Rev. Adv. Mater. Sci., vol. 44, pp. 313-325, 2016.

[20] L. S. Walker, V. R. Marotto, M. A. Rafiee, N. Koraktar and E. L.Corral, "Toughening in graphene ceramic composites", ACS Nano, vol. 5 no. 4, pp. 3182-3190, 2011.

[21] J. Liu, H. Yan, K. Jiang, "Mechanical properties of graphene platelet-reinforced alumina ceramic composites", Ceramics International, vol. 39, no. 6, pp. 6215-6221, 2013.

[22] Yanju Liu, Haiyang Du, Liwu Liu and Jinsong Leng, "Shape memory polymers and their composites in aerospace applications: a review", Smart Materials and Structures, vol. 23, no. 2, 2014.

[23] R. Das, C. Melchior, K. M. Karumbaiah, "Self-healing Composites for Aerospace Applications" Advanced Composite Materials for Aerospace Engineering: Processing, Properties and Applications, pp. 333-364, 2016. 